\title{
OESOPHAGEAL RECONSTRUCTION IN CHILDREN USING INTRATHORACIC COLON*
}

\author{
BY \\ CHARLES D. SHERMAN, JR. and DAVID WATERSTON \\ From The Hospital for Sick Children, Great Ormond Street, London
}

This paper records our experience in the use of colon for oesophageal reconstruction in children, and includes a summary by one of us of similar cases operated on in other centres.

In 1894 Bircher reconstructed the oesophagus using a subcutaneous skin tube. Since then many methods of reconstruction have been tried both clinically and experimentally; these methods have included the use of stomach, skin tubes, jejunum, colon, aorta, inert tubes, etc. The early work has been well summarized by Ochsner and Owens (1934) and the more recent work by Mahoney and Sherman (1954).

Sandblom (1948) was the first to use the colon for reconstruction in atresia of the oesophagus, and it was his work that stimulated one of us (D.J.W.) to attempt this method using a slightly different technique. Lundblad (1921) had previously used the colon for reconstructing the oesophagus in a 3-yearold child suffering from a corrosive stricture. He also showed (1934) that such an oesophagus grew with the child and functioned satisfactorily 15 years after operation.

\section{Indications for Reconstruction of Oesophagus}

Atresia of Oesophagus without Tracheo-oesophageal Fistula. In our experience this type of deformity is always associated with a very wide gap between the blind ends of the oesophagus; the lower segment is rarely more than $1 \mathrm{~cm}$. in length. In these cases also, the stomach and intestines are extremely small; the child has been unable to swallow liquor amnii before birth and the intestinal tract has therefore not developed adequately. Both these facts, i.e., the wide gap and the smallness of stomach and intestines, make a primary anastomosis impracticable.

We feel that it is unwise to bring the stomach up to the apex of the chest in the newborn, and that in these cases no primary anastomosis should be attempted. The upper oesophagus should be

\footnotetext{
*A paper read at the meeting of the British Association of Paediatric Surgeons in London in July, 1956.
}

brought out on the left side of the neck for drainage of saliva and a gastrostomy made for feeding. The subsequent reconstruction of the oeosophagus should be delayed until the baby is thriving and gaining weight.

As the absence of gas below the diaphragm does not rule out the presence of a tracheo-oesophageal fistula (Waterston, 1954), it follows that these cases should have an exploratory right thoracotomy as a preliminary to the oesophagostomy and gastrostomy.

Atresia of Oesophagus with Tracheo-oesophageal Fistula. Unquestionably the treatment of choice in these cases is a primary anastomosis, and we feel that with careful freeing of the upper and lower segments of oesophagus a tension-free anastomosis can be obtained in over $90 \%$ of such cases. However, if the distance between the ends of the oesophagus is great and there is any doubt about the soundness of the suture line, then an oesophagostomy and gastrostomy should be done after the fistula and lower segment of the oesophagus have been tied off in the chest.

Reconstruction can then be carried out when the baby is in good general condition.

Stricture of the Oesophagus. Severe stricture affecting the long segment of the oesophagus, whether caused by the swallowing of corrosives, or by the acid reflux from an incompetent cardia, may sometimes necessitate wide resection. If a primary anastomosis is not feasible, then reconstruction with colon is an attractive method of reconstruction.

Miscellaneous Conditions. There is a growing feeling among surgeons that the oesophagus should almost never be anastomosed to the stomach for any condition. In a child whose oesophageo-gastric junction has been resected (for example, for bleeding varicosities) it is felt that interposition of a loop of colon between the lower oesophagus and stomach is a preferable method to anastomosis of oesophagus 
TABLE

COLON TRANSPLANTS IN CHILDREN

\begin{tabular}{|c|c|c|c|c|c|}
\hline & Case & Condition & Colon & Route & Follow-up \\
\hline *†Battersby (Indianapolis) & $\begin{array}{l}1 \\
2 \\
3 \\
4 \\
5 \\
6 \\
7 \\
8\end{array}$ & $\begin{array}{l}\text { Atresia } \\
\text { Stricture } \\
\quad, \\
\text { ", } \\
\text { Atresia }\end{array}$ & $\begin{array}{c}\text { Right } \\
\text {," } \\
\text {," } \\
\text {," } \\
\text { Left }\end{array}$ & $\begin{array}{c}\text { Retrosternal } \\
\text { R. posterior chest } \\
\text { ", ", ", } \\
\text { Left posterior chest }\end{array}$ & $\begin{array}{l}3 \text { years. Eats everything } \\
\text { Died } 3 \text { weeks post-operatively. ? cause } \\
\text { All have survived } \\
\text { Developed marginal ulcer and perforated }\end{array}$ \\
\hline / & $\begin{array}{r}9 \\
9 \\
10 \\
11 \\
12\end{array}$ & ," & Right & Retrosternal ", & $\begin{array}{l}\text { Three late deaths of ? cause with bowel necrosis } \\
3 \text { cervical fistulae. All healed spontaneously } \\
2 \text { patients living not longer than } 1 \frac{1}{2} \text { years follow-up }\end{array}$ \\
\hline $\begin{array}{l}\text { †Haight and DeWeese } \\
\text { (Ann Arbor) }\end{array}$ & $\begin{array}{l}13 \\
14\end{array}$ & ," & $\ddot{\prime \prime}$ & $\ddot{\prime \prime}$ & $\begin{array}{l}1 \text { death secondary to pulmonary complications } \\
\text { (13). Fistulae in neck in } 2 \text { (13 and 14). Follow-up } \\
\text { less than } 6 \text { months }\end{array}$ \\
\hline * † Jewett (Buffalo) & $\begin{array}{l}15 \\
16\end{array}$ & $\begin{array}{l}\text { Stricture } \\
\quad,\end{array}$ & ", & ", & $\begin{array}{l}\text { Small bowel obstruction (adhesions) at } 6 \text { weeks } \\
\text { relieved by operation, follow-up } 2 \text { months }\end{array}$ \\
\hline †Koop (Philadelphia) & $\begin{array}{l}17 \\
18 \\
19\end{array}$ & $\begin{array}{l}\text { Atresia } \\
\quad,, \\
,,\end{array}$ & ", & ,", & $\begin{array}{l}\text { Appendiceal stump used for } 1 \text { anatomosis and } \\
\text { patients died. Cases } 18 \text { and } 19 \text { live and well } \\
1-2 \text { years }\end{array}$ \\
\hline * $†$ Nadal (Portland) & 20 & TE fistula & , & , & Follow-up 1 year. No complications \\
\hline$\dagger$ Rickham (Liverpool) & 21 & Atresia & Left & Left posterior chest & $\begin{array}{l}\text { Died of ? damage to blood supply by diaphragm- } \\
\text { atic hernia }\end{array}$ \\
\hline $\begin{array}{l}\text { *Sherman and Dale } \\
\text { (Rochester) }\end{array}$ & $\begin{array}{l}22 \\
23\end{array}$ & TË fistula & Right & Retrosternal & $\begin{array}{l}\text { Live and well } 2 \frac{1}{2} \text { years. Mild stasis post-operatively } \\
\text { Cervical fistula with stenosis requiring revision } \\
\text { Alive and well } 2 \frac{1}{2} \text { years }\end{array}$ \\
\hline *Waterston (London) & $\begin{array}{l}24 \\
25 \\
26 \\
27\end{array}$ & $\begin{array}{c}\text { Atresia } \\
,, \\
,,\end{array}$ & $\begin{array}{c}\text { Left } \\
,, \\
,\end{array}$ & $\begin{array}{c}\text { Left pleural cavity } \\
, ", ",\end{array}$ & $\begin{array}{l}1 \text { death, others alive and well. Distal anastamosis } \\
\text { to oesophagus above diaphragm }\end{array}$ \\
\hline †Campbell (Geneva,N.Y.) & 28 & $\begin{array}{l}\text { Uther nor } \\
\text { Stricture }\end{array}$ & Right & Retrosternal & $\begin{array}{l}\text { Cervical fistula at } 12 \text { days, alive and well at } \\
3 \text { months }\end{array}$ \\
\hline *†Day (Jacksonville) & 29 & , & , & ", & $\begin{array}{l}\text { Colon mobilized at 1st stage. Extensive adhesions } \\
\text { at } 2 \text { nd and patient died? secondary to pro- } \\
\text { longed surgery }\end{array}$ \\
\hline * tGrant (New York) & 30 & 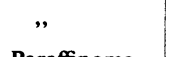 & $T_{-1}$ & " & $\begin{array}{l}\text { Died at } 7 \text { weeks. Mediastinal abscess. Pulmon- } \\
\text { ary complications }\end{array}$ \\
\hline Kergin (Toronto) & 31 & Paraffinoma & Transverse & Postero mediastinal & Alive and well at 3 years \\
\hline †Koop (Philadelphia) & 32 & $\begin{array}{c}\text { Bleeding varices } \\
,, \quad,, \quad\end{array}$ & $\begin{array}{l}\text { Oesophago-g } \\
\text { position } 0\end{array}$ & $\begin{array}{l}\text { trectomy with inter- } \\
\text { transverse colon }\end{array}$ & $\begin{array}{l}2 \text { patients moribund before surgery, died. } \\
3 \text { rd case alive and well at } 4-5 \text { months }\end{array}$ \\
\hline †Clatworthy (Cleveland) & $\begin{array}{l}34 \\
35\end{array}$ & ", $\quad$, & ", & ", & ? \\
\hline
\end{tabular}

$\dagger$ Personal communication.

to stomach. Although not utilized by us, this procedure has been performed recently by other surgeons in patients who have continued to bleed from oesophageal varices despite various shunting procedures (Table).

\section{Two Methods of Reconstruction}

We describe two methods of reconstruction. The first (devised by Waterston) is reconstruction with transverse colon transplanted iso-peristaltically into the left posterior chest on a pedicle containing the left colic artery. This method has been used by one of us (D.W.) in four cases, and the first baby was operated on on September 22, 1951. Figs. 1-5 show diagrammatically the stages of the procedure as applied to a case of atresia of the oesophagus without tracheo-oesophageal fistula.

This method has the advantage of preserving intact the all-important cardiac sphincter mechanism between the oesophagus and stomach.
J.P. was born on December 11, 1952, of healthy parents. His mother was a midwife and had been taught that hydramnios in the mother was not infrequent in cases of oesophageal atresia. As she had hydramnios she persuaded her obstetrician to pass a stomach tube on the baby immediately after birth (Waterston, 1955). She was right (Fig. 7). No gas below the diaphragm suggested, but did not rule out, the absence of tracheo-oesophageal fistula.

At the first operation on December 12, 1952 (by D.W., anaesthetist Dr. B. G. B. Lucas), using endotracheal oxygen with a relaxant, a right axillary thoracotomy through the fourth interspace was done. The blind end of the upper oesophagus was freed and the end marked with a black stitch. The absence of a tracheo-oesophageal fistula was confirmed. The lower oesophagus consisted of a small blind pouch extending for $1 \mathrm{~cm}$. above the diaphragm. The distance between the two ends of the oesophagus was more than $10 \mathrm{~cm}$. The thoracotomy wound was closed in layers. A high gastrostomy was done through the linea alba using the smallest Malecot self-retaining catheter. 


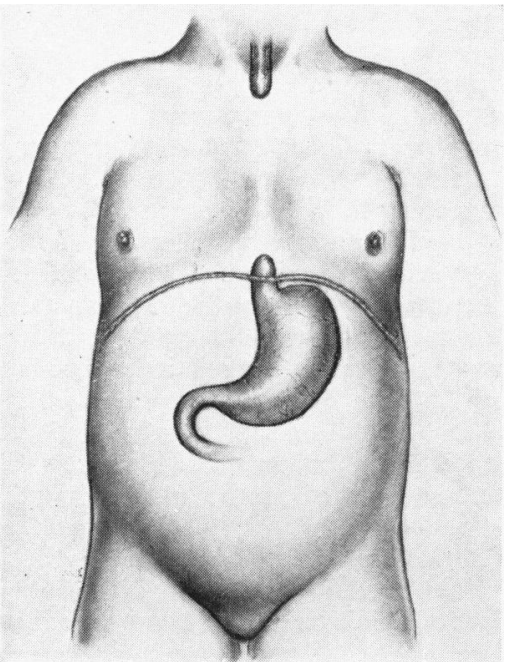

FIG. 1.

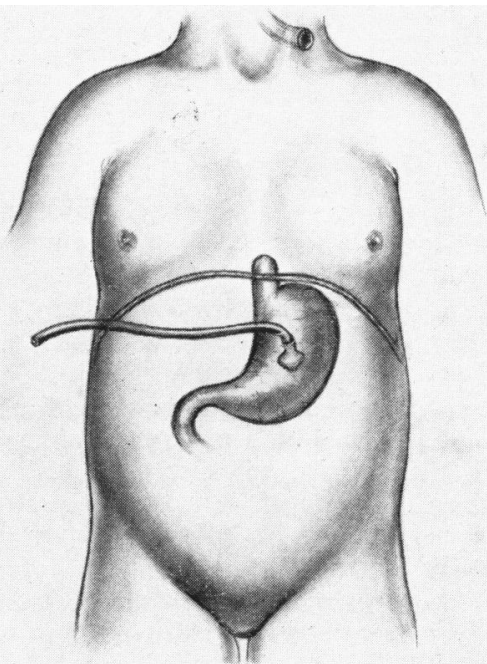

FIG. 2.

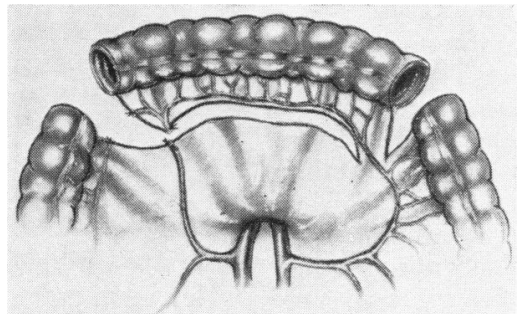

FIG. 3.

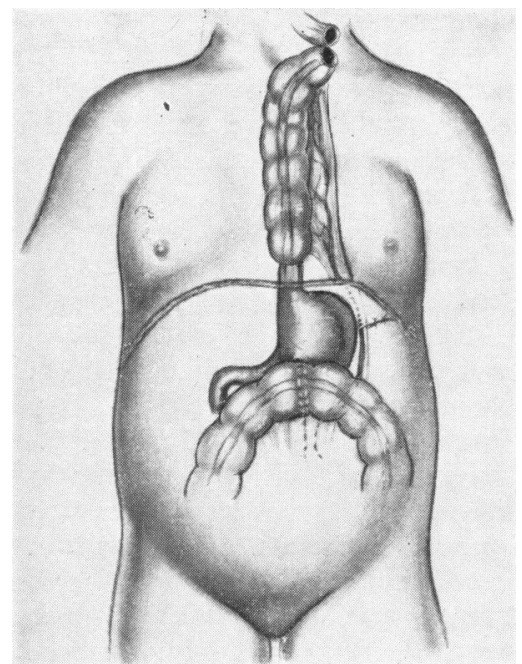

Fig. 4.

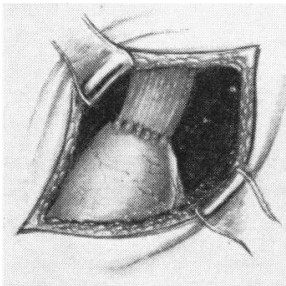

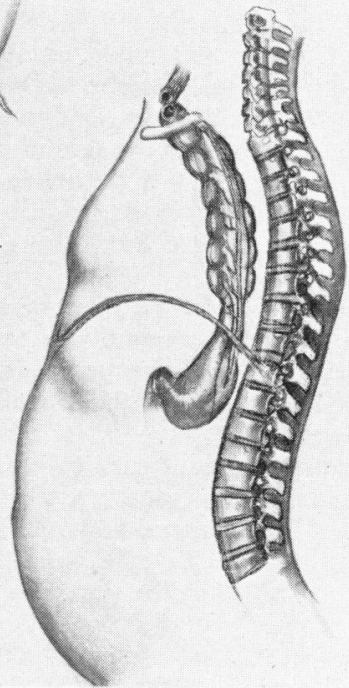

Fig. 5. 
Through a transverse incision $4 \mathrm{~cm}$. in length above the left clavicle and dividing part of the clavicular head of the sternomastoid, the upper pouch of oesophagus was brought out from the upper mediastinum; it was opened at the terminal marking stitch and its edges stitched to the skin with interrupted silk.

Post-operatively, the baby was fed by gastrostomy, oral feeds being also given which drained through the oesophagostomy.

The second operation (D.W.) on June 7, 1953 (anaesthetist Dr. B. G. B. Lucas), endotracheal oxygen and ether with relaxant were used.

Through a transverse abdominal incision the transverse colon was isolated on a pedicle containing the left colic artery. The middle colic artery was divided close to its origin. Continuity of the colon was re-established by end-to-end anastomosis using one layer of interrupted 0000 silk.

The proximal end of the isolated transverse colon was closed and attached by a nylon stitch to the skin at the right end of the skin incision. The wound was then closed in layers leaving the distal opening of the transverse colon as a colostomy at the left end of the skin incision.

Post-operatively the isolated loop of transverse colon was irrigated through the colostomy with a solution containing streptomycin and sulphasuxidine.

The third operation was performed eight days later. The anaesthetic was again endotracheal oxygen and ether with a relaxant.

With the baby on the right side the previous transverse abdominal incision was extended laterally through the tenth interspace into the chest. The diaphragm was incised towards but not into the oesophageal hiatus; the spleen was removed. The marking stitch attaching the colon to the abdominal wall was divided and the isolated loop of transverse colon brought up into the left chest. The pedicle containing the left colic artery lay without tension, and there was adequate length of colon to reach up to the neck.

An incision was made just below the cervical oesophagostomy and the apex of the pleura opened by blunt dissection; the proximal end of the transverse colon was then brought out to the skin of the neck.

The distal stump of oesophagus was then freed and an end-to-end anastomosis made between it and the distal end of the colonic loop, using a single layer of 0000 interrupted silk.

The incision in the diaphragm was then closed with interrupted linen thread, care being taken not to close it too tightly round the pedicle containing the left colic artery. The thoraco-abdominal wound was then closed in layers.

Feeding was continued by gastrostomy.

The fourth operation was performed on August 24, 1953. Under general anaesthesia an end-to-end anastomosis was carried out between the oesophagostomy and the colonic loop in the neck; the skin was closed over the anastomosis (Fig. 4A).

Oral feeding, which had been kept up since birth, was started again two days after the fourth operation; the baby was very soon able to take his full feeds by mouth and thereafter gastrostomy feeds were withdrawn. The gastrostomy wound closed spontaneously after withdrawal of the gastrostomy tube, apart from a very small gastric fistula which leaked occasionally. This was closed by oversewing it on August 20, 1955.

The baby remained very well until September 20, when part of the stomach which had herniated through the incision in the diaphragm underwent torsion in the left chest and became acutely distended. He became rapidly shocked with complete collapse of the left lung and displacement of the mediastinum to the right.

The tension within the chest was relieved by re-opening his gastrostomy, with a dramatic improvement in his general condition.

On October 15 the diaphragmatic hernia was repaired and the diaphragm stitched more carefully round the pedicle containing the left colic artery. Since then he has continued to thrive and develop normally. He eats everything and has no difficulty at all with swallowing. He eats his meals as quickly and with as much enjoyment as other children.

The radiographic appearances on barium swallow show the reconstructed oesophagus to function well; the segment of transverse colon shows peristalsis of the colonic type, i.e., the meal is pushed on by a 'mass movement' type of peristalsis. It empties itself rapidly into the stomach; the cardiac sphincter is competent and no reflux can be elicited.

Two other babies have been operated on by this technique. They are now 4 and 5 years old and both are thriving and swallowing normally.

A fourth case was operated on in 1954; an attempt was made to combine stages 2 and 3 into one operation. The colonic loop was pulled up too tightly into the neck, thereby 'bowstringing' the artery of supply. The colonic loop became gangrenous and the child succumbed a few hours after operation.

The second method of reconstruction uses right colon transplanted isoperistaltically in the retrosternal position (Charles D. Sherman, Jr.). At the initial emergency procedure in infants with oesophageal atresia of tracheo-oesophageal fistula, it is felt wise to delay reconstruction; the cervical oesophagus is brought out in the left neck and a gastrostomy is done the following day. At a later date, varying from a few weeks to a number of months depending on the patient's condition, oesophageal reconstruction is performed. Preoperative bowel preparation consists chiefly in the administration of neomycin and sulphathalidine to prepare the lower ileum and colon for section. At operation a longitudinal incision extending to the xiphoid is utilized and the right colon mobilized by cutting the lateral attachments. The length of the right colon is estimated and the collateral vascular supply evaluated by placing a bull-dog clamp on the ileo-colic artery. During the waiting period to ascertain whether the blood supply to the caecum is 
maintained, appendectomy is done by the routine manner. The ileum is sectioned approximately 4-6 in. proximal to the ileo-caecal valve. This leaves a long segment of ileum which can be utilized and anastomosed to the cervical oesophagus if it proves to be necessary to gain adequate length. The transverse colon just to the left of the middle colic artery, taking care to avoid injury to the marginal vessel, is sectioned and after sectioning the ileo-colic vessels the entire transplant can be swung to the neck. The blood supply to the entire transplant then comes through the middle colic vessels. The transplant is carried through the substernal tunnel which is cleared by blunt dissection immediately beneath the sternum in the anterior mediastinum. The reconstruction is terminated by end-to-end anastomosis of the caecum or ileum to the cervical oesophagus, by anastomosis of the lower end of the transplant into the anterior wall of the stomach, and by end-to-end ileo-transverse colostomy. The wound is closed with interrupted fine silk sutures. The gastrostomy is left in place and may heal spontaneously, or may be closed at a later date. Pneumothorax sometimes occurs during the operative dissection and is handled by simple needle aspiration at the end of the procedure. The procedure is illustrated (Fig. 6).

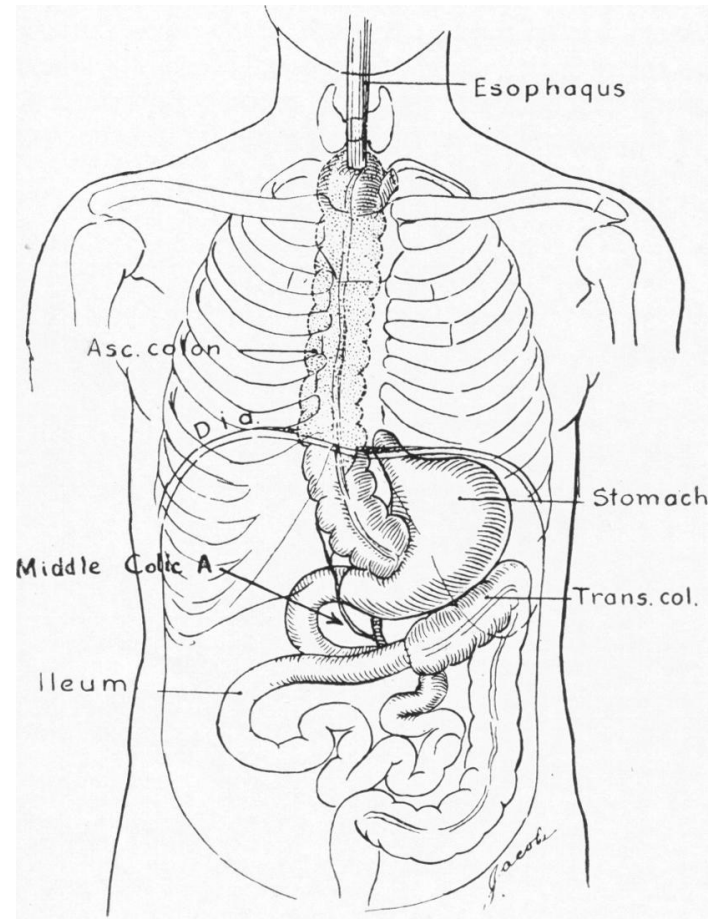

Fig. 6.

\section{Other Methods of Transplantation}

Studies of the colonic blood supply have shown that infrequently one or other of the above methods may be impracticable because of lack of collateral circulation. Should this be true it is imperative that surgeons be acquainted with other possibilities. These include (1) utilization of the transverse colon with the blood supply based upon the middle colic and right superior colic vessels; (2) utilization of transverse colon with the blood supply based upon the middle colic artery and left superior colic artery; (3) utilization of the descending colon with the blood supply based upon the middle colic artery; (4) utilization of caecum and terminal ileum with the blood supply based upon the ileo-colic artery; and (5) various methods of utilization of the jejunum and stomach.

\section{Discussion}

The type of reconstruction used by Waterston and others has the advantage of preserving the normal oesophago-gastric junction. Since the colon is not anastomosed to the stomach there is no danger of later peptic digestion of the colon and perforation. Although Sherman feels that this is a relatively unusual complication, it has occurred in at least one case. This reconstruction leaves the patient with the least disturbance to normal physiology. The main disadvantage to this procedure is the fact that the blood supply must be brought through the diaphragm and considerable care must be taken to make sure that the opening in the diaphragm is neither so large as to result in a hernia, nor so small that it causes vascular obstruction. There have been some post-operative problems with herniation through the diaphragmatic opening and this may account for vascular obstruction with subsequent necrosis of the colonic transplant and death of the patient (Table). Sherman feels that there will be a larger percentage of patients who have inadequate collateral circulation to nourish the transplant when dependance is placed upon the inferior colic artery to carry blood all the way to the mid-transverse colon.

The advantage of the right colon transplant as utilized by Sherman and others lies in the fact that the anterior mediastinal route seems a very satisfactory one because it is the shortest distance to the neck and because it does not interfere with the blood supply to the transplant. A disadvantage as compared with Waterston's method seems to lie in the possibility of peptic ulceration of the lower end of the colon where it is anastomosed into the stomach. Although it is felt that the colon is much more resistant to peptic digestion than is the oesophagus or jejunum, it must be admitted that at least one case has had colonic erosion with perforation (Table). 
Although the right colon transplants have been done in one stage, as contrasted with three stages for the transverse colon transplant as done by Waterston, at least one patient has required a subsequent minor operation for revision of a stenosis at the cervical anastomosis.

The question whether the cervical anastomosis should be done at the initial reconstruction or the second stage is a matter of opinion. Sherman feels that this anastomosis should be done at the initial reconstruction thereby saving a certain number of patients a later reconstruction. Should the initial anastomosis break down his experience would indicate that these cervical fistulae will heal spontaneously and will rarely necessitate secondary reconstruction. Waterston, on the other hand, feels that it is safer to delay the cervical anastomosis for a subsequent stage.

Will the use of colon transplantation decrease the mortality in tracheo-oesophageal fistula and atresia? The current mortality rate around the world in patients with tracheo-oesophageal fistula and atresia varies tremendously from somewhere around $20 \%$ to approximately $80 \%$, depending upon the area and the type of medical centre where these patients are handled. Associated congenital anomalies also cause some mortality. A large proportion stems from the fact that these patients are frequently in very poor condition when seen initially by the surgeon. However, at least some of this mortality is caused by (1) the surgeon's compulsion to do a primary anastomosis even though it looks as though it might break down subsequently; and (2) the added operating time in a poor risk patient entailed by mobilization of the stomach and various other methods of performing a difficult anastomosis. It may be that by avoiding these two factors one can decrease the mortality rate. In these difficult cases we believe that delaying reconstruction and subsequent repair with a colon transplant will yield an overall case mortality rate much lower than will be attained by going ahead with emergency initial reconstruction.

What is the significance of colonic peristalsis to these transplants? Limited experience suggests that an isoperistaltic transplant works better than an antiperistaltic transplant. This is certainly true using small bowel which maintains a considerably more active peristalsis than does the colon. We do not believe that this question has been definitely settled, however. It is certain that colonic peristalsis is very slow and that it probably plays very little part in propelling the food from the mouth to the stomach. Both Harrison (1949) and Syring (1914) have reported difficulty in cases in which antiperistaltic small bowel loops were used. However, the left colon has been used in an antiperistaltic manner in a number of cases with apparently little difficulty (Lundblad, 1921; Waterston, 1955; Toupet, 1951). Further experimental work and further clinical evaluation on this point are needed.

What can be done to decrease the incidence of cervical fistulae? Although this has not been a serious clinical problem, it has remained a troublesome complication even when the anastomosis has been done by so experienced a surgeon as Gross (Table). Sherman has tried wrapping the anastomosis (in an adult) with a free graft of peritoneum, but this patient developed a cervical fistula. The utilization of small bowel rather than caecum for the anastomosis has not seemed to make any significant difference as to whether a fistula develops. If this continues to be a troublesome complication, it may be advisable to use catgut entirely for the anastomosis in order to prevent splitting silk for a prolonged period of time. Waterston feels that it is probably better to delay the cervical anastomosis for a subsequent minor operation than to risk fistula and subsequent stenosis. The incidence of fistula formation seems lower when the cervical anastomosis is delayed.

Concern about the blood supply to a transplant arises when utilizing right colon as described by Sherman. In an occasional patient the middle colic artery has seemed to be tight when placed anterior to the pylorus. In those cases it is certainly safer to bring the entire transport and blood supply posterior to the stomach thereby eliminating the possibility of obstruction in the pyloric area.

\section{Conclusion}

Although reconstruction of the oesophagus by colon transplant is still in the developmental stage, sufficient experience has been accumulated to suggest that further trial and evaluation are worth while. Several years of further observation of these patients will be necessary before we can with certainty justify our initial enthusiasm for the use of this procedure.

\section{REFERENCES}

Battersby, J. S. (1953). Surg. Forum, 4, 279.

Dale, W. A. and Sherman, C. D., Jr. (1955). J. thorac. Surg., 29, 344. Goligher, J. C. and Robin, I. G. (1954). Brit. J. Surg., 42, 283.

Harrison, A. W. (1949). J. thorac. Surg., 18, 316.

Kelling, G. (1911). Zbl. Chir., 38, 1209.

Lundblad, O. (1921). Acta chir. scand., 53, 535

Lundblad, (1934). Ibid., 75, 73.

Mahoney, E. B. and Sherman, C. D., Jr. (1954). Surgery, 35, 937.

Ochsner, A. and Owens, N. (1934). Ann. Surg., 100, 1055.

Orsoni, P. and Toupet, A. (1950). Presse méd., 58, 804

Sandblom, P. (1948). Acta chir. scand., 97, 25.

Sherman, C. D., Jr., Mahoney, E. B., Dale, W. A. and Stabins, S. J. (1955). Cancer, 8, 1198

Syring, - (1914). Disch. Z. Chir., 128, 260. Quoted by Ochsner and Owens.

Toupet, A. (1951). Rev. Chir. (Paris), 70, 70.

Waterston, D. J. (1954). In Recent Advances in Paediatrics, ed Gairdner, D. London.

(1955). In Modern Trends in Obstetrics and Gynaecology

(Second Series), ed. Bowes, K., p. 294. London. 
amongst those over the age of 5 ; the heaviest mortality being amongst infants; a description is given of the exudate found in the faeces of a case of dysentery, but there is no mention of how often a similar exudate is found in a salmonella infection.

A very comprehensive chapter contains valuable material and observations on epidemiology of these $E$. coli infections and analyses the work for and against their being the cause of epidemics; there is a review of epidemiological investigations in which the $\mathrm{H}$ and the phage typing were employed. As so often happens when many articles are abstracted and described in a small space, some parts of this chapter are not as detailed as might be desirable, and this can confuse the reader. However, the references are accurate and doubtful statements were clarified when the original articles were consulted.

An extremely valuable chapter on the morbid anatomy at necropsy is based on the personal observations of $G$. Ilgner, who had access to material which is rarely obtained in England, as all of it was fixed within a very few hours of death.

One chapter deals exhaustively with the problems of protein and carbohydrate metabolism and the experiments on amino-acid metabolism are particularly interesting. The formation of biogenic amines is said to be caused by deamination of amino-acids instead of decarboxylation and a few of the references are not listed, which can be irritating; another curious mistake is the description of Aristophanes as a philosopher and attributing to him a saying of Heraklitos.

Adam's own contribution is on the pathogenesis, treatment and clinical presentation of gastro-enteritis, the last of which he explains on anatomical and biochemical findings; he feels that parenteral infections cause some cases, basing part of his argument on what might be a dangerous foundation, that is on negative bacteriological results. In this comprehensive chapter there are details of some types of enteritis seldom, if ever, seen in England, including enteritis necroticans due to Clostridium welchii.

The possible paths by which infection can be spread and many techniques to make the manoeuvres for admitting, nursing and handling babies safe, are fully discussed. Although many of the methods are widely used, few now practice a 'napkin round' and many would object to the use of a $1 \frac{1}{2} \%$ solution of formaldehyde for washing floors.

\section{Ninth International Congress of Paediatrics}

The Ninth International Congress of Paediatrics will be held in Montreal, Canada, from Friday, July 19 to Thursday, July 25, 1957, under the chairmanship of Dr. Alan Ross, Professor of Paediatrics, the Montreal Children's Hospital, Montreal 25, Canada.

\section{British Paediatric Association Memorandum on the Use of Radio-iodine in Paediatrics}

In 1956 the British Paediatric Association set up a subcommittee to consider the use of radioactive iodine in paediatrics in relation to possible carcinogenic effects. Its members sought advice from Dr. E. E. Pochin, of University College Hospital, and Dr. L. F. Lamerton, of the Physics Department, Institute of Cancer Research, Royal Cancer Hospital, who presented the data and explained the calculations on which the following conclusions are based.

1. That no form of radio-iodine should be used to treat an over-active gland in a child and that therefore the use of radio-iodine for the therapy of thyrotoxicosis did not require discussion.

2. That there appeared to be increased vulnerability to the late effects of external $x$-irradiation with doses of the order of 250 reps, or more, at least up to the age of 6 years, and that there was no evidence of the age at which vulnerability decreased to the adult level.

3. That it was not possible to feel sure that test doses of ${ }^{131} \mathrm{I}$ as low as $1 \mu \mathrm{c}$ might not be hazardous in children.

4. That, bearing in mind that the half-life of ${ }^{131} \mathrm{I}$ was 192 hours and of ${ }^{132}$ I $2 \cdot 3$ hours, ${ }^{132}$ I was not likely to be hazardous in test doses of about $4 \mu \mathrm{c}$, a dose which is adequate for the usual tests which are completed within the first four to six hours, but not for those requiring longer times.

5. That ${ }^{131}$ I should not be used in children when the employment of ${ }^{132} I$ would give the information which is needed. In the calculations leading to this conclusion several 'safety factors' are involved which make it doubtful whether any harm will actually result from the use of small doses of ${ }^{131} \mathrm{I}$, and it must be left to the individual paediatrician to decide whether its use is justifiable in the investigation of any specific clinical problem.
(Signed) D. V. Hubble
J. H. Hutchison
P. R. Evans

\footnotetext{
We regret that in the paper entitled 'Oesophageal Reconstruction in Children Using Intrathoracic Colon' by Charles D. Sherman and David Waterston (Archives of Disease in Childhood, 32, 11) the source of the paper as stated was incorrect; this should have read 'From the Department of Surgery, University of Rochester, New York, and The Hospital for Sick Children, Great Ormond Street, London'.
}

Correction 